\title{
Evaluation of the Diagnostic Accuracy of Modified Alvarado Scoring System in Comparison to Histopathological Results in Acute Appendicitis
}

\author{
Nirmala, Mysore Jayakumar, Shahanuma Shaik and Rajendra Naidu* \\ PES Institute of Medical Sciences, Andhra Pradesh (India)
}

\begin{abstract}
Background: Acute appendicitis even today remains the commonest cause of acute abdomen needing surgical intervention. In developing countries the clinical diagnosis still poses a challenge to the surgeon and advanced radiological investigations are not cost effective while histopathological diagnosis remains the gold standard. The Modified Alvarado score augments the accuracy of diagnosis of appendicitis thus reducing the rate of negative appendicectomy.

Methods: Patients admitted with clinical findings suggestive of Acute appendicitis were evaluated by applying Modified Alvarado scoring system. Those patients with Alvarado scores above 5 were subjected to appendicectomy. The Modified Alvarado score was correlated with that of histopathologial features of appendicectomy specimens.

Results: The histopathological features of appendicitis was seen in $87.8 \%$ of the cases whose scores were more than 7 while negative appendicitis was seen in $38.1 \%$ whose scores were between 5-7.The sensitivity, specificity, positive predictive value and negative predictive value of Alvarado scores in our study were $87.80 \%, 38.01 \%, 73.50 \%$ and $61.50 \%$ respectively.

Conclusions: The study concludes that the Modified Alvarado scoring system is more sensitive in diagnosing acute appendicitis with reference to the histopathological findings.
\end{abstract}

Keywords: Acute Appendicitis, Modified Alvarado Scoring System, Appendecectomy.

\section{Introduction}

Acute appendicitis is one of the commonest surgical emergencies and appendicectomy being the most common emergency operation performed with lifetime prevalence of approximately 1 in $7 .^{[1,2]}$ The clinical presentation of acute appendicitis are varied from fever, vomiting, right iliac fossa (RIF) pain, tenderness and rebound tenderness to atypical vague abdominal pain. Early diagnosis and intervention is very much necessary to prevent morbidity and cost. Approximately $6-7 \%$ of the population suffers from this disease during their lifetime. ${ }^{[3,4]}$

In order to increase the diagnostic accuracy and to reduce the high negative appendicectomy rate, various scoring systems and imaging modalities are devised. The Alvarado scoring described in 1986 has been in use in surgical practice in the diagnosis of acute appendicitis. ${ }^{[5]}$

This study was planned to evaluate the modified Alvarado Scoring system with that of Histopathological findings in patients operated upon as acute appendicitis.

\section{Materials and Methods}

This is a prospective study which was conducted in the department of Pathology in a tertiary care hospital for the period Jan 2015-Aug 2015. A total of 62 consecutive adult patients admitted during this period who presented with clinical findings suggestive of Acute appendicitis were evaluated by applying Modified Alvarado score(Table 1).And relevant laboratory investigations were done. Those patients with Alvarado scores above 5 were subjected to appendicectomy. The modified Alvarado score was later correlated with the histopathological findings.

The study was approved by the institutional ethical committee. A standard protocol was followed and written consent obtained from patient and/ relative.

Inclusion Criteria: The adult patients of both sexes presenting with pain in the abdomen with tenderness in the right iliac fossa were included in the study.

Exclusion Criteria: 1) Alvarado score of less than 5. 2) Patients presenting with diffuse abdominal pain suggestive of generalized peritonitis. 3) Patients with history of Diabetes mellitus and immunocompromised status. 4) Pregnant women.

Statistical Correlation: The data was entered into MS Excel 2007 version and further analyzed using stata 14 . The descriptive data were analyzed as follows: Categorical were analyzed using mean and standard deviation. For 
inferential statistics, diagnostic test and Chi-square test was used.

\section{Results}

In this study, 62 patients were evaluated by physical and laboratory examinations before subjecting them to surgery. Out of the 62 patients, $48(77.41 \%)$ were males and 14 $(22.58 \%)$ were females in the ratio of $1.58: 1$. The age range was $19-42$ years with a mean of $26 \pm 5.7$ yrs. (Table 2)

On the basis of Modified Alvarado Scores the patients were segregated into two groups. Group I (Score>7) and Group II (Score 5-7).

In Group 1 out of 41 patients 36 (87.8\%) had histopathological features of acute appendicitis and 5 patients (12.2\%) showed negative results. In Group II out of 21 patients, $13(61.9 \%)$ were histopathogically confirmed as acute appendicitis while 8 patients (38.1\%) showed negative results.

In Group II, the negative appendicitis rate was significantly higher than Group I (38.1\% Vs12.2\%; P<0.018) (Table 3) with an overall negative appendicectomy rate of $31.7 \%$.
The overall sensitivity, specificity, positive predictive value and negative predictive value of Alvarado score for acute appendicitis were $87.80 \% 38.01 \% 73.50 \%$ and $61.50 \%$ respectively.

The Histopathological features of acute appendicitis in the surgically removed appendix were as follows: (Table 4).

Acute appendicitis-41 cases (Fig. 1), Suppurative appendicitis-4 cases (Figs. 2, 3), Gangrenous appendicitis1 case (Fig. 4), perforated appendix- 1 case and Periappendicitis -2 cases (Fig.5).

\section{Discussion}

Acute Appendicitis is still a common surgical emergency and poses a diagnostic challenge for the operating surgeon. [6] The negative appendicectomy rates may arise due to judgemental error in clinical diagnosis. Hence to aid the diagnosis and reduce the negative appendicectomy rates Alvarado in 1986 introduced a scoring system. The diagnosis of Acute appendicitis using Modified Alvarado Scoring System is based on three symptoms, three signs and one laboratory finding. It is used as an adjunct to clinical

Table 1: Modified Alvarado Scoring System

\begin{tabular}{|c|c|c|}
\hline \multicolumn{2}{|c|}{ Clinical Features } & Score \\
\hline Symptoms & $\begin{array}{l}\text { Migratory RIF pain } \\
\text { Anorexia } \\
\text { Nausea/ Vomiting }\end{array}$ & $\begin{array}{l}1 \\
1 \\
1\end{array}$ \\
\hline Signs & $\begin{array}{l}\text { Tender RIF } \\
\text { Rebound tenderness } \\
\text { Elevated temperature } \\
\text { Leukocytosis }>10 \times 10^{9} / \mathrm{L}\end{array}$ & $\begin{array}{l}2 \\
1 \\
1 \\
2\end{array}$ \\
\hline \multicolumn{2}{|l|}{ Total } & 9 \\
\hline
\end{tabular}

Table 2: Age and Sex wise distribution (19-42 yrs)

\begin{tabular}{|c|c|c|}
\hline Age in years & Group I (41) & Group II (21) \\
\hline $19-23$ & $16(12 / 4)$ & $7(5 / 2)$ \\
\hline $24-28$ & $14(11 / 3)$ & $4(3 / 1)$ \\
\hline $29-33$ & $05(4 / 1)$ & $1(1 / 0)$ \\
\hline $34-38$ & $04(3 / 1)$ & $\mathrm{NIL}$ \\
\hline $39-43$ & $02(2 / 0)$ & \\
\hline
\end{tabular}

*Figures in paranthesis indicate males versus females respectively

Table 3: Correlation of Alvarado score with histopathological findings $(n=62)$

\begin{tabular}{|l|c|c|}
\hline \multirow{2}{*}{ HISTOPATHOLOGY } & Group I Group II & p-value \\
\cline { 2 - 3 } & $\mathbf{n = 4 1} \mathbf{n = 2 1}$ & \\
\hline Abnormal Appendix & $36(87.8 \%) 13(61.9 \%)$ & $\mathrm{P}=0.018$ \\
Normal Appendix & $5(12.2 \%) 8(38.1 \%)$ & \\
\hline Total & $41(100 \%) 21(100 \%)$ & \\
\hline
\end{tabular}


Table 4: Histopathological findings of the operated specimens of Appendix

\begin{tabular}{|l|c|c|}
\hline Histopathology findings & $\begin{array}{c}\text { Group 1 } \\
(\mathbf{n = 4 1 )}\end{array}$ & $\begin{array}{c}\text { Group 11 } \\
\text { (n=21) }\end{array}$ \\
\hline Acute Appendicitis & $29(70.73 \%)$ & $12(57.14 \%)$ \\
Suppurative Appendicitis & $4(9.75 \%)$ & $0(0 \%)$ \\
Gangrenous Appendicitis & $1(2.43 \%)$ & $0(0 \%)$ \\
Perforated Appendix & $1(2.43 \%)$ & $0(0 \%)$ \\
Periappendicitis & $1(2.43 \%)$ & $1(4.76 \%)$ \\
Normal Appendix & $5(12.20 \%)$ & $8(38.09 \%)$ \\
\hline
\end{tabular}

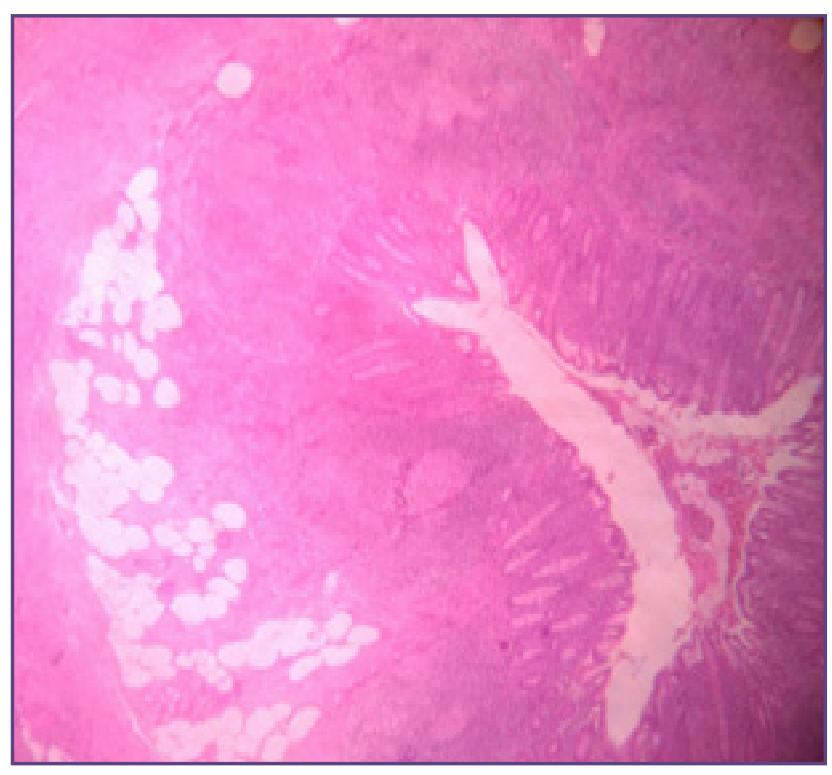

Fig. 1: Photomicrograph showing Acute appendicitis with lymphoid hyperplasia (H\&E, X 100)

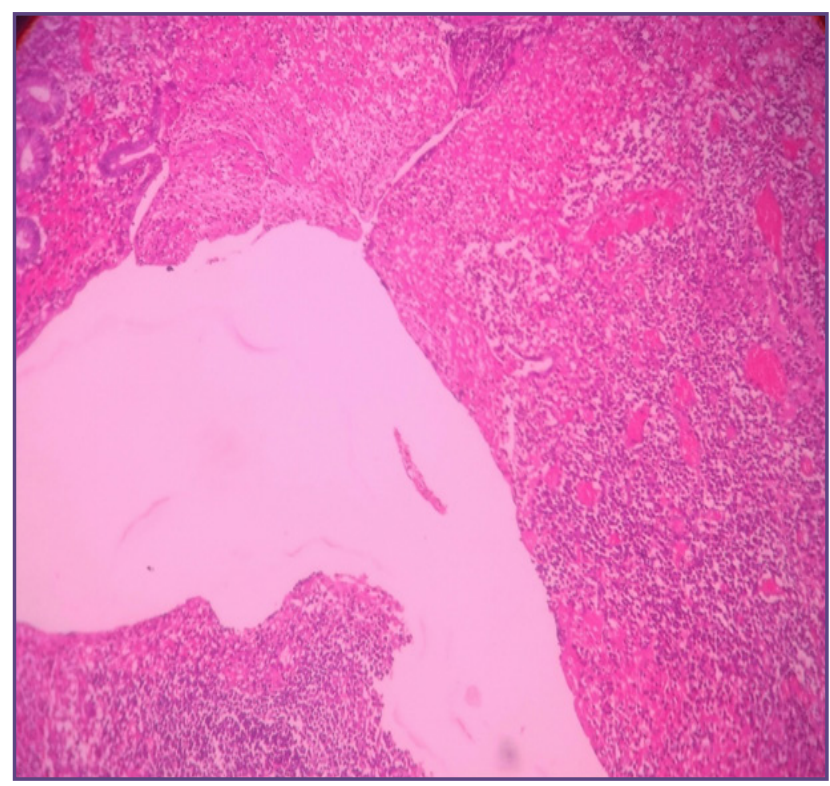

Fig. 2: Photomicrograph showing mucosal ulceration and abscess formation in Acute suppurative appendicitis (H\&E, X100)

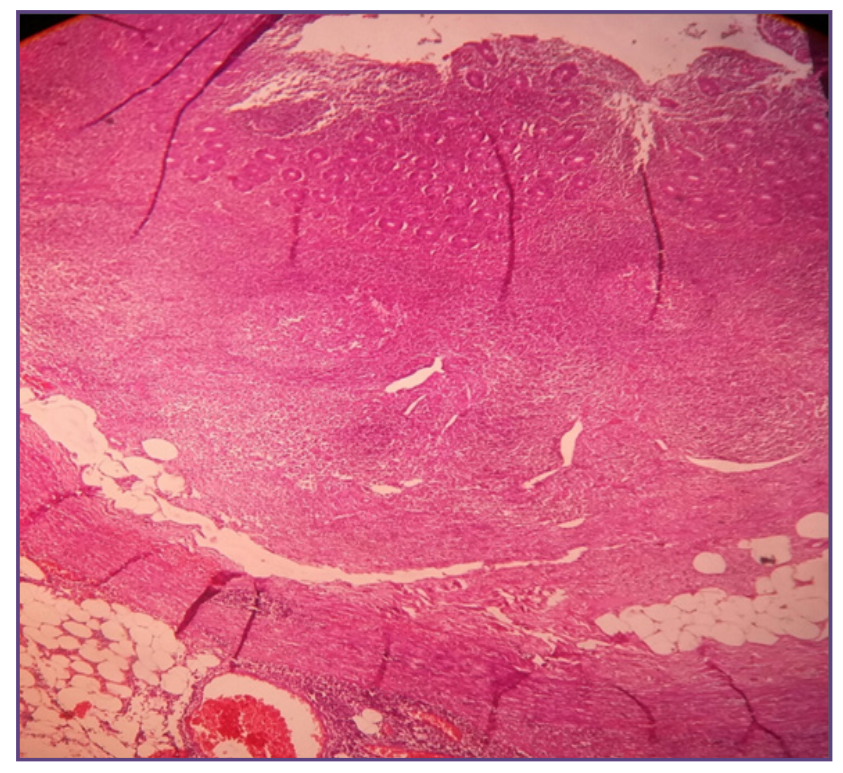

Fig. 3: Photomicrograph showing Acute suppurative appendicitis (H\&E,X100)

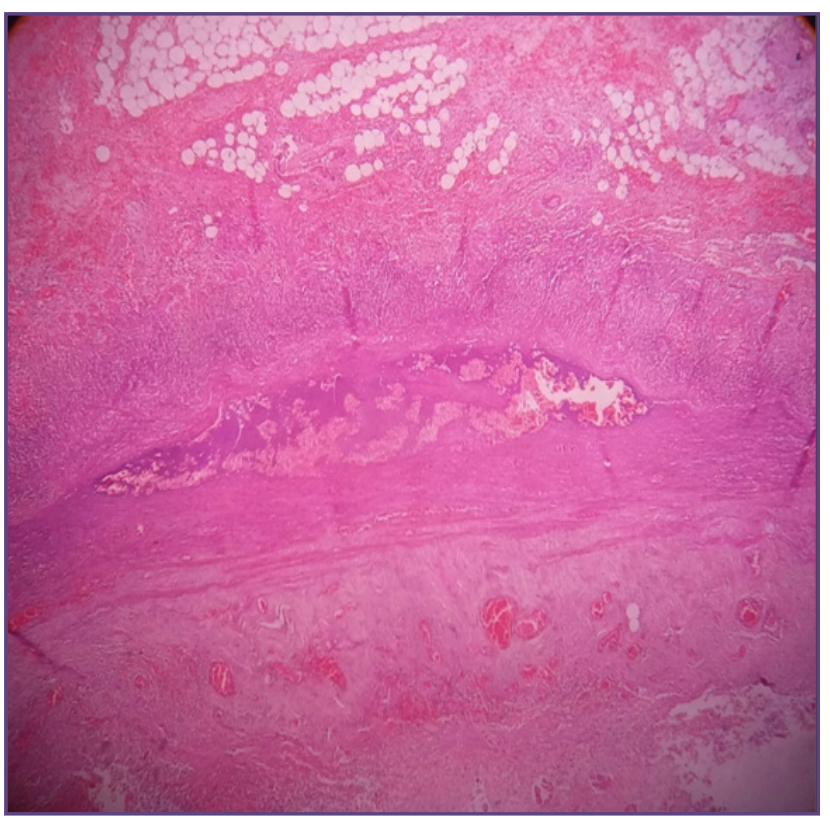

Fig. 4: Photomicrograph showing thrombosed vessels in gangrenous appendicitis (H\&E, X400) 


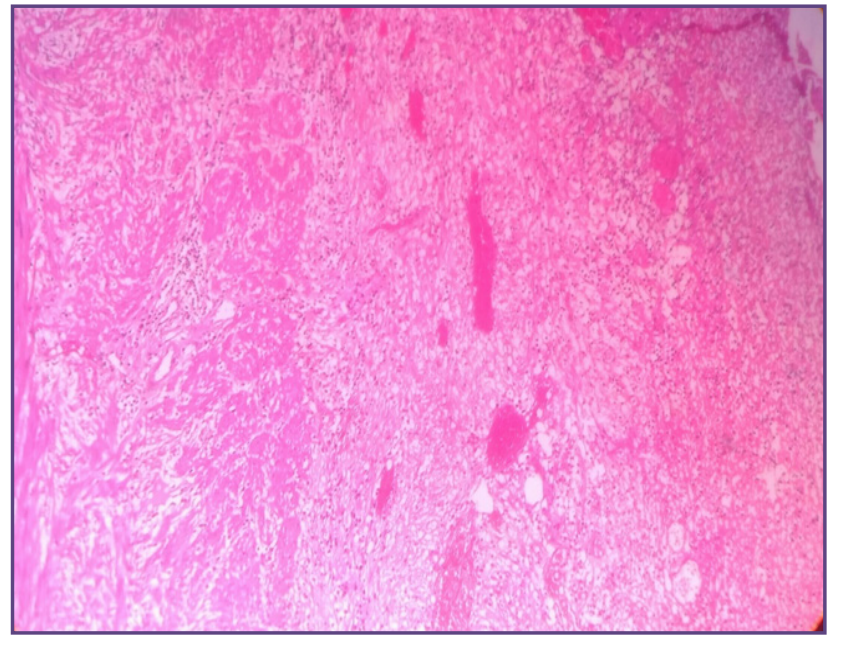

Fig. 5: Photomicrograph showing Peri appendicitis (H\&E, $\mathrm{X100)}$ shows acute inflammatory cell infiltrates.

diagnosis in reducing the false positive appendecectomy rates. The surgical intervention was recommended for all patients with a score of $\geq 7$ and observation for those between 5-6.

In our study and that of Ana $\mathrm{J}$ et al the Alvarado scoring is highly sensitive in diagnosis of Acute Appendicitis in adults. ${ }^{[7]} \mathrm{A}$ score of 7 and above is strongly predictive of acute appendicitis and surgery is recommended..$^{[8,9]}$

In the present study there was a male preponderance with younger age group of 20 to 28 years. Similiar findings were noted with other studies. ${ }^{[4,7,10]}$

The patients in our study who had Alvarado score above 7, had histopathological features of Acute appendicitis in $87.8 \%$ of the cases and only $12.2 \%$ had no evidence of Appendicitis. While in patients with score of less than 7, $61.9 \%$ had features of Acute appendicitis and $38.1 \%$ did not have appendicitis histopathologically.

In the present study the overall rate of negativity appendicectomy was $31.7 \%$. This is quite comparable with other published literature where up to $40 \%$ rate of negative appendicectomies are reported. ${ }^{[11,12]}$

The sensitivity and specificity of Alvarado score in our study was $87.80 \%$ and $38.01 \%$ while in other studies it was $94.20 \% \& 70 \%, 66 \% \& 81 \%$ and $97.79 \% \& 77.77 \%$ respectively. ${ }^{[7,13,14]}$

The overall positive predictive value and negative predictive value of Alvarado score in our study was $73.50 \%$ \& $61.50 \%$ respectively which is comparable with other studies $86.90 \% \& 69.80 \%, 94.29 \% \& 72.40 \%$ and $94.7 \%$ \& $41.6 \%$ respectively. ${ }^{[13,14,15]}$
The findings of Appendicitis with suppuration (9.75\%) gangrene $(2.43 \%)$ and perforation $(2.43 \%)$ reflects delay in seeking medical help. The perforation rate $(2.43 \%)$ in our study was similar $(2.14 \%)$ to a study done by Riti et al ${ }^{[10]}$ but suppuration $(0.7 \%)$ and gangrenous appendicitis $(1.42 \%)$ was less comparatively.

In order to improve the diagnostic accuracy and delaying appendicectomy, the risk of perforation and sepsis may increase. And on the other hand with reduced diagnostic accuracy the negative appendicectomy rate increases.

The scoring system is less sensitive in women of child bearing age and poses a diagnostic challenge as other gynaecological conditions may mimic acute appendicitis. One has to avoid unnecessary appendecectomy but on the other hand missing the diagnosis may risk perforation and morbidity. Under such circumstances the other diagnostic modalities such as laparoscopy can be used in pregnant women. ${ }^{[7]}$

The Modified Alvarado Scoring system helps even the General Practitioners and Medical Officers of the Primary Health Centres to make an early referral to the qualified surgeon. The incidence of Acute appendicitis and its complications are evident with Alvarado score of more than 7 and its significance to justify early surgical intervention.

\section{Conclusion}

Modified Alvarado scoring system is easy, simple, non invasive and highly sensitive in preoperative diagnosis of Acute appendicitis. The scores over 7 in adults is highly predictive of acute appendicitis and early surgical intervention is indicated to avoid complications like suppuration, gangrene and perforation. And patients with a score between 5-7 needs revaluation and probably a contrast enhanced C T Scan will reduce the rate of appendicectomy.

\section{Reference}

1. Ramchandra J, Sudhir M, Satyanarayana BA. Evaluation of Modified Alvarado Score in preoperative diagnosis of acute appendicitis. Journal of Evolution of Medical and Dental Sciences,2013;2:9019-9029.

2. Jagdish BK, Mukesh DK, Palekar HD, Upendra P. Utility of Alvarado score in diagnostic acute appendicitis in children: A cross sectional study.National Journal of Medical Research,2014;4:125-127.

3. Rajashekar J, Uday M, Naveen N. Modified Alvarado score and its application in the diagnosis of Acute Appendicitis. International Journal of Contemporary Medical Research,2016;3:1398-1400.

4. Kodliwadmath HB, Bhaskaran A, Prasad CSBR, Basavaraj M, Ambikavathy M, Vasantkumar G. Evaluation of Modified Alvarado score in the diagnosis of Acute Appendicitis and its correlation with Ultrasonography and histopathology. J Clin Biomed Sci,2011;1(4):149-157. 
5. Alvarado A. A practical score for the early diagnosis of acute appendicitis. Ann Emerg Med, 1986;15(5): 557-564.

6. Jones K, Penna AA, Dunn EL, Nadalo L, Mangram AJ. Are negative appendicectomies still acceptable? Am J Surg,2004;188(6):748-754.

7. Ana J, Syed AS, Muhammad S, Muhammad Z, Umbreen $\mathrm{R}$, Yasir H. Alvarado scoring system in prediction of Acute appendicitis. Journal of the College of Physicians and Surgeons Pakistan, 2011; 21(12):753-755.

8. O'Connell PR. The vermiform appendix. In, Williams NS, Bulstrode CJ, O`Connell PR (ed). Bailey \& Love's Short Practice of Surgery, $2^{\text {th }}$ edition. Boca Raton, FL, CRC press,2013;1199-1214.

9. Ercan I, Elif H, Sibel A, Figen P,Tan C, Ahmet NJ, Ersan A. Efficiency of unenhanced MRI in the diagnosis of acute appendicitis: Comparison with Alvarado scoring system and histopathological results. European Journal of Radiology, 2011;80:253-258.

10. Riti TKS, Aniruna D.A Retrospective study of histopathological features of Appendecectomy specimensWhat all can expect? Journal of Medical Sciences and Health,2016;2:6-12.
11. Nanjundaiah N, Ashfaque M, Venkatesh S, Kalpana A, Priya SA. A Comparative study of RIPASA score and Alvarado score in the diagnosis of acute appendicitis.Journal of Clinical and Diagnostic Research,2014;8(11):3-5.

12. Nishikant G, Sajid M, Ravikumar C, Sachin DM. Determination of Sensitivity and Specificity of Modified Alvarado score and Ultrasonography in patients with Acute appendicitis. Journal of Krishna Institute of Medical Sciences University,2015;4(2):89-99.

13. Dey S, Pradip KM, Anil KB, Bikram K, Kincha LB, Varun KS. Alvarado scoring in Acute appendicitis- A Clinico Pathological Correlation. Indian J Surg,2010;72(4): 290-293.

14. Ratnadeep SS, Girish LJ, Milind SC. Correlation of Alvarado score for acute appendicitis with pathological appendicitis, Int Surg J.2016;3(3):1451-1455.

15. Malhotra MK, Sharma RG, Goyal S, Panwar U, Singal KK, Dwivedi S. Is diagnostic accuracy of Alvarado scoring feasible in acute surgery for management of acute appendicitis? Bangladesh Journal of Medical Sciences,2016;15(2):166-171.

*Corresponding author:

Dr.Rajendra Naidu, Professor of Pediatrics,PES Hospital,Kuppam-517425, Andhra Pradesh, India

Phone: +919845147702

Email: rajnaidu57@yahoo.co.in

Date of Submission : 09.08.2017 Date of Acceptance : 20.09.2017

Financial or other Competing Interests: None.
Date of Publication : 28.01.2018 